\title{
Computer, Whom Should I Hire? - Acceptance Criteria for Artificial Intelligence in the Recruitment Process
}

\author{
Vanessa Laurim \\ Technical University of \\ Munich \\ laurim@in.tum.de
}

\author{
Selin Arpaci \\ Technical University of \\ Munich \\ selin.arpaci@tum.de
}

\author{
Barbara Prommegger \\ Technical University of \\ Munich \\ barbara.prommegger@tum.de
}

\author{
Helmut Krcmar \\ Technical University of \\ Munich \\ helmut.krcmar@tum.de
}

\begin{abstract}
In the war for talents, the need for appropriate tools to fill open positions with the right talents is becoming increasingly important for employers. AI-based technologies simplify recruiters' daily work and increase the efficiency of the recruitment process by replacing time-consuming approaches. However, little is known about the reactions of stakeholders to AI-based recruiting. Thus, this paper aims to identify personal and contextual factors that influence the acceptance of AI-based technologies in the recruitment process. Based on the interviews with recruiters, managers, and applicants involved in the recruitment process, we present that transparency, complementary features of the AI tools, and a sense of control play key roles in the acceptance of AI-based technology when used for recruiting. The findings contribute to research on the adoption of AI in the recruitment process and provide recommendations on the use of AI technologies when hiring talents.
\end{abstract}

\section{Introduction}

With the rapid changes in technology and the need for innovation, knowledge-based economy has become the dominant discourse in global economic restructuring [1]. The more the importance of knowledge increases, the more the reliance on talent increases. Whysall and her colleagues [2] define talent as the critical driver of corporate performance. The required knowledge of workers has also increased from $17 \%$ to $60 \%$ in just over a decade. Thus, the competitive advantage of attracting, developing, and retaining talent continues to mount [2].

Rapid digitization will increase the importance of human resources in companies. According to the Economist [3], the post-covid world will accelerate the infusion of data-enabled services into more aspects of life. Frankiewicz and Premuzic [4] expect "digital transformation to be an even bigger imperative for organizations in the short term future." They claim that digital transformation is more about people than about technology. When the new layer of demand by startups is added to the demand of established companies for highly skilled employees on the talent pool, human capital becomes the most important source of competitive advantage in the "war for talent." Therefore, it is important for companies to get great talent to remain compatible on the fast-changing job market.

Over the last 20 years, exponential technology development has revolutionized recruitment, changing both employer practice and candidate expectations. Many companies started to use different technological platforms to communicate with and attract talent as part of their e-recruitment strategies in the war for talent [5]. E-Recruiting was the first successful step toward recruitment automation [6] representing a complete process, from the search for potential candidates, through the selection of personnel, to the communication and management of the application process. A recruiting system makes the recruiter's life easier by automating everyday tasks such as organizing $\mathrm{CVs}$ and managing candidates during the recruitment process [7]. For example, AI in the forms of chatbots and machine learning [8] are now widely used to compete in the war for talent.

The great potentials of big data in the application and hiring process is only just beginning to be exploited [9]. This potential and the high expectations from AI and recruiting technologies can only be realized through user's acceptance. However, AI-based technologies are often still judged with caution [9]. Since little is known about the reactions of candidates to AI-based recruiting [10], many Human Resource (HR) professionals still doubt algorithms' recommendations and decisions. The AI tools leave many yet-unanswered questions about their accuracy, and the ethical, legal, and privacy implications that they introduce. Considering these doubts and unanswered questions, the acceptance by candidates and employees will be an indicator of the successful adoption of AI recruiting technologies. Therefore, this paper investigates:

Where can AI be used for recruiting and how do applicants, recruiters and managers react to the usage of AI in the recruitment process?

To answer these questions, we conducted a case study based on qualitative interviews with different 
stakeholders involved in the recruitment process. Our aim is to identify personal and contextual factors that influence the user's acceptance of AI-based technologies in the recruitment process.

\section{Theoretical Background}

\subsection{Types of $A I$ used in recruitment}

Three different types of AI-based systems are discussed in the recruiting context depending on whether the use of AI supports the employee or the applicant [11]. For the first type, the AI job recommender systems match a candidate profile and the available job opportunities, and then prioritize job opportunities for the candidate [12]. Second, Curriculum Vitae (CV) recommender systems can match job requirements with applicant profiles to support recruiters' decision making. According to Strohmeier and Piazza [13], this search for suitable candidates is supported by knowledge-based search engines to pre-select potential candidate by automating search task and offering semantic information about job seekers. Third, the CV parsing technologies offer another option to analyze the resume of candidates and rank them according to their skills. The $\mathrm{CV}$ data acquisition can support recruiters as the underlying algorithm to decide on its own which applications should be preferred for a certain job [14]. The term automated recruitment is synonymous to AI recruitment, where AI refers to any intelligent agent that automates recruiting activities by acting rationally. The difference between AI and the classical linear algorithms lies in the type of processing. While a linear algorithm always executes its commands following a certain rule, AI learn and draw logical conclusions [8].

\subsection{Applications of AI within the recruitment process}

In this paper, the recruitment process is treated as a business process which, in agreement with Davenport and Short [15], is defined as a series of logically related tasks for achieving a well-defined outcome for internal or external stakeholders. The traditional recruitment is a linear process with successive tasks. It covers every path of the candidate. This recruitment process can be divided into five different phases: job advertisement, jobs search, information/communication, application, and decision. In this work, we on the procurement of employees for the company itself, not for the external companies. In the context of recruiting, the spectrum ranges from tools that support HR in creating unbiased job descriptions to tools that support in the pre- and final selection of candidates. Table 1 illustrates how AI can
Table 1. Application of AI in the recruitment process Application of AI

\begin{tabular}{|c|l|}
\hline \multicolumn{1}{|c|}{ Phase } & \multicolumn{1}{c|}{ Application of AI } \\
Jobvertisements & $\begin{array}{l}\text { Machine learning and language analysis } \\
\text { supports recruiters in the formulation of job } \\
\text { advertisements, selection, and control online } \\
\text { channels. }\end{array}$ \\
\hline Job search & $\begin{array}{l}\text { AI helps to find the right job for a job seeker } \\
\text { considering skills, geographical, and } \\
\text { demographic data. }\end{array}$ \\
\hline $\begin{array}{c}\text { Information/ } \\
\text { Communication }\end{array}$ & $\begin{array}{l}\text { Self-learning chatbots that answer frequently } \\
\text { asked questions from applicants or propose } \\
\text { the right job. }\end{array}$ \\
\hline Application & $\begin{array}{l}\text { CV parsing to optimally present applicant } \\
\text { data. Aplication wizard and digital assistants } \\
\text { can take over the task of writing an } \\
\text { application for a job for the applicant. }\end{array}$ \\
\hline Evaluation and \\
selection & $\begin{array}{l}\text { AI analyzes components of the application } \\
\text { and evaluates candidates and, thus, predicts } \\
\text { the fit of an applicant. Tests and assessments } \\
\text { can also be intelligently evaluated. }\end{array}$ \\
\hline
\end{tabular}

support numerous points of contact between the candidate and the company during the e-recruitment process.

Job advertisements: New recruiting services on the market use machine learning and language analysis to analyze job advertisement for gender bias. Startups are using predictive analysis tools to code gender biased language and find the most effective words from its database to help recruiters neutralize job descriptions. Their database is built from peer-reviewed academic research [16]. The New York Times reported in an article on a company that uncovered more than 25,000 phrases that indicate gender bias. "Top-tier" and "aggressive", sports or military analogies decrease the proportion of women who apply for a job, while phrases like "partnerships" and "passion for learning" attract more women [17]. The AI behind this service can support recruiters in the publication of job advertisements by drawing a conclusion from the following existing data: the most promising keywords in an ad and the right choice of external channels (social media and job boards), which have been the most successful tool in attracting applicants with potential for the job advertised [9].

Job search: The conventional searching job boards are based on the input of search parameters. AI improves the search results on a much broader and finer basis. Candidates can upload their CV or link their data from social networks to the career portal. AI analyzes the entire career path, including education and acquired professional certificates, and filters out suitable results from a job portal. The educational and the professional qualifications, together with the skills and competencies are related to the maturity level, the seniority of the candidate, and the career, as well as the location are considered [9].

Information/Communication: $\mathrm{AI}$ and natural language processing are changing the way artificial 
assistant communicate and interact with users [18]. Chatbots, as conversational agents help to improve the existing processes when it comes to the first point of contact between the candidate and the company, i.e., the career page, the job offers, and finally the submission of the application [7]. Self-learning chatbots, which answer candidates' questions can help save time [7]. The digital assistant supports job seekers, and HR staff in their search for information, for example by answering FAQs or helping job seekers to find a suitable position based on their skills and preferences.

Application: Applicants upload their resume and the CV parser automatically transfers the data to prestructured data fields in the applicant tracking system [13]. Individual text modules are analyzed, and the parser recognizes which components must be transferred to which data fields based on the typical text modules. This technology reduces effort for applicants and recruiters. Sophisticated parsing technologies use artificial neural networks and deep learning methods for text comprehension [19]. One step further is the approach by Teetz [20] that fills complex application forms via an intelligent assistant without the applicants writing and uploading their CV. This approach makes all the application data available online, and an artificially intelligent assistant also collect, prepare, and send the data to the applicant management system. The corresponding competences and skills can be checked and compiled by a certification authority, i.e., via OpenBadges.

Evaluation and Selection: AI-based technology is widely used in the evaluation and selection steps as the automated pre-screening supports recruiters in the selection of candidates. First, AI is used to check parameters like candidates' skills, or salary expectations. AI-controlled software recognizes not only hard skills, but even job-relevant soft skills and personality traits of candidates that are not evident from the written CVs and cover letters. Furthermore, rules for diversity management can prevent social discrimination and improve equal opportunities. Additionally, it is becoming more common for recruiters and employers to request that candidates submit a video as part of their job application. Software analyzes short videos of the candidates and creates scientific personality profiles of the candidates by registering choice of words, articulation, or facial expressions and gestures. By using natural language processing, computer vision, and pattern recognition methods personality traits are explored and first impressions are formed [21]. The results of the analysis are then compared with the competence profile of the job advertised and the organizations' values, resulting in a better fit of the candidate and the organization.

\subsection{Criteria influencing user acceptance of AI in recruitment}

Only few papers investigated technology acceptance within the recruitment process [22]. Furthermore, there are only few theories explaining acceptance of AI-based technologies [23]. For this reason, we investigate the reasons for acceptance or rejection of $\mathrm{AI}$ in the recruitment process using Technology Acceptance Model (TAM) by Davis [24, 25], complemented by Technology Readiness by Parasuraman and Colby [26] as our theoretical lens in order to consider the novel aspects of AI-based technologies. TAM considers the factors perceived ease of use and perceived usefulness as the main two factors influencing the decision whether to use a new technology by assessing the extent to which it will help him/her to perform his/hers job better [24, 27]. Perceived usefulness is most frequently affected by job relevance, complexity, and social influence. Perceived ease of use is most frequently affected by attitude, anxiety, trialability, perceived enjoyment [28]. Technology readiness is an overall state of mind resulting from discomfort, optimism, insecurity, and innovativeness [29]. Discomfort comes from a perceived lack of control, whereas optimism depends on the increased feeling of control and flexibility, and inse curity results from the distrust of technology. Thus, we choose sense of control and trust as the complementary dimensions. Table 2 provides an overview of the criteria relevant for AI-based technology acceptance.

Table 2. Criteria for AI-based technology acceptance

\begin{tabular}{|c|c|}
\hline \multicolumn{2}{|r|}{ Perceived usefulness } \\
\hline $\begin{array}{l}\text { Job } \\
\text { relevance }\end{array}$ & $\begin{array}{l}\text { The capabilities of a system to enhance an } \\
\text { individual's job performance [28]. }\end{array}$ \\
\hline Complexity & $\begin{array}{l}\text { The degree to which an innovation is perceived as } \\
\text { being difficult to use [28]. }\end{array}$ \\
\hline $\begin{array}{c}\text { Social } \\
\text { influence }\end{array}$ & $\begin{array}{l}\text { Person's perception that most people who are } \\
\text { important to him think he should or should not } \\
\text { perform the behavior in question [28]. }\end{array}$ \\
\hline \multicolumn{2}{|r|}{ Perceived ease of use } \\
\hline Attitude & $\begin{array}{l}\text { The degree to which a person likes or dislikes the } \\
\text { object [28]. }\end{array}$ \\
\hline Anxiety & $\begin{array}{l}\text { An individual's apprehension, or even fear, when } \\
\text { she/he is faced with the possibility of using } \\
\text { computers [28]. }\end{array}$ \\
\hline Trialability & $\begin{array}{l}\text { The degree to which an innovation may be } \\
\text { experimented with before adoption [28]. }\end{array}$ \\
\hline $\begin{array}{l}\text { Perceived } \\
\text { enjoyment }\end{array}$ & $\begin{array}{l}\text { The extent to which the activity of using a specific } \\
\text { system is perceived to be enjoyable in its own } \\
\text { right, aside from any performance consequences } \\
\text { resulting from system usage [28]. }\end{array}$ \\
\hline \multicolumn{2}{|r|}{ Technology readiness } \\
\hline $\begin{array}{l}\text { Sense of } \\
\text { control }\end{array}$ & $\begin{array}{l}\text { The positive view of technology that offers people } \\
\text { increased control, flexibility, and efficiency in } \\
\text { their lives. A perceived lack of control would give } \\
\text { a person the feeling of being overwhelmed by the } \\
\text { technology [26]. }\end{array}$ \\
\hline Trust & $\begin{array}{l}\text { The secureness of technology and its ability to } \\
\text { work properly [26]. }\end{array}$ \\
\hline
\end{tabular}




\section{Research Method}

The overall aim of this paper is to identify acceptance criteria concerning AI-based technology in the recruitment process. Studies have shown that AI recruiting is feasible, although AI recruitment algorithms can be biased and can lead to discrimination [14]. Little is known in the literature about the reactions of the different stakeholders involved in the AI recruitment process. Consequently, this paper examines the acceptance of AI recruiting system using three stakeholders, engaged in the recruitment process: recruiters, managers, and applicants.

Case selection and data collection: To obtain a broad picture of the AI recruitment system different perspectives, we defined three target groups for our interviews: recruiters, managers, and applicants. In overall, 15 interviews were conducted to gain a broad understanding about the user acceptance regarding the adoption of AI in recruiting. The case study was conducted in an international medical technology company based in Germany. Table 3 provides an overview of the characteristics of the interviewees.

Recruiters were responsible for talent acquisition and management in a company. They ensure that the positions that are important for the company's success are filled with the right employees, from trainees to professionals. Managers were involved in the process from the very beginning due to their professional skills. The have access to the recruiting system and evaluate candidates according to their knowledge and experience. All applicants were currently in a job application process and could therefore draw on real experience with $\mathrm{AI}$ in the recruitment process.

The people interviewed were chosen based on the decision to cover all the recruitment process stakeholders. Furthermore, to capture different opinions and experiences, different age groups were considered. Recruitment of interviewees took place through personal contact or e-mail. All interviewees in the study have a strong connection to the topic of IT due to their course of study or the companies they work for.

Interviews: We used semi-structured interviews as a survey method to ensure that the respondents had enough freedom to describe their overall attitude toward e-recruiting and AI-based technologies, and to express their expectations. First, we asked the participants about their experiences in the application and hiring process. To introduce AI in recruiting, we asked for the general attitude of the respondents toward AI, and AI as part of the recruitment process. Afterwards, we played through two scenarios of $\mathrm{AI}$ in recruiting with the stakeholders. First, we asked them about their behavioral intentions for each scenario, which examined whether the respondents would actually be prepared to use the
Table 3. Overview of interviews

\begin{tabular}{|c|c|c|}
\hline $\begin{array}{l}\text { Stake- } \\
\text { holder }\end{array}$ & Background & Position \\
\hline 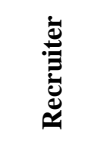 & $\begin{array}{l}25-35 \text { years } \\
\text { old, } 5 \text { females, } \\
2-10 \text { years of } \\
\text { experience }\end{array}$ & $\begin{array}{l}2 \text { Recruiter } \\
1 \text { Senior Recruiter } \\
1 \text { Recruiting Consultant } \\
1 \text { Talent Mgt. Associate }\end{array}$ \\
\hline 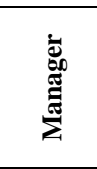 & $\begin{array}{c}30-55 \text { years } \\
\text { old, } \\
5 \text { males, } \\
\text { 5-20 years of } \\
\text { experience }\end{array}$ & $\begin{array}{l}1 \text { Vice President } \\
1 \text { Fellow Software Engineer } \\
1 \text { Sales Director } \\
1 \text { Manager AI } \\
1 \text { Head of Sales \& Marketing }\end{array}$ \\
\hline & $\begin{array}{c}20-35 \text { years } \\
\text { old, } \\
2 \text { fem. } / 3 \text { males, } \\
1 \text { - } 15 \text { years of } \\
\text { experience }\end{array}$ & $\begin{array}{l}2 \text { Working Students } \\
1 \text { Mgt. Associate of the COO } \\
1 \text { Junior Supplier Quality Eng. } \\
1 \text { Account Manager }\end{array}$ \\
\hline
\end{tabular}

options described. Moreover, we asked the participants which requirements the AI technology has to fulfill to make them use it. Additionally, we analyzed whether there is fear of substitutability when AI is part of the recruitment process. Finally, we determined further expectations of employers and applicants for AI-based recruiting tools to subsequently formulate the acceptance criteria from the employer's and applicant's point of view.

Data analysis: The coding process followed a deductive approach [30]. We identified the codes based on our theoretical lens. The coding takes into account the theoretical basis of acceptance research, as statements were sought in a manner that reflect the variables proposed by Lee [28]. After coding the interviews, we choose to investigate the reasons for acceptance or rejection of $\mathrm{AI}$ in the recruitment process by building on the factors drawn from the Technology Acceptance Model (TAM) by Davis [24, 25], combined with the key aspects of the dimensions from Parasuraman [26] and variables suggested by Lee [28] in order to be more explanatory within our acceptance variables. We then used these as our theoretical lens to investigate the acceptance model of both active and passive users for a technology. We grouped the variables under the central determinants ease of use and the perceived usefulness, and technology readiness to consider the novel aspect of AI-based technologies [27].

\section{Results}

In general, we could not observe any effects of respondents' individual characteristics (including gender and age) on their perceptions of the AI in recruitment. All interviewees had the opinion that AI will complement and extend human capabilities. In the sequel, we will explain the required acceptance criteria per recruiting phase and stakeholder group. Table 4 
maps the acceptance variables to the stakeholders and phases of the recruitment process.

Job advertisement: For the process step job advertisement we identified job relevance as the main acceptance criteria. The support of AI in the creation of job advertisements met with positive feedback from the recruiters. Results from this study suggest that recruiter's motivation to use AI in their daily business were influenced strongly by the capabilities of a system to enhance an individual's job performance. All study participants were ready to immediately integrate the AIbased software into their everyday work. The recruiters agreed that job advertisements are often formulated too superficially. One recruiter reported how difficult it is to formulate appropriate ads:

"You don't take enough time for formulating the job descriptions. And you simply don't have your strengths in it. A recruiter is not necessarily also a good copywriter. (Recruiter)."

Today, job postings are often still checked under a dual control principle which can be taken over by an AI. One interviewee stated:

"At this point [offormulating job advertisements], I can imagine an AI totally well, because it is only about the text. What the competition does or whether the text is okay from a legal point of view is very interesting. (Recruiting and Marketing Consultant)."

Nevertheless, from the recruiters' perspective the technology must be able to analyze and evaluate several languages and familiar with the general regulations. The AI must not only be multilingual, but also meet the requirements of the respective country/state specified rules and regulations. Furthermore, the integration of AI software solution into the applicant tracking system held importance for the recruiters. They stated that the creation of job postings must be quick and easy.

Job search and Information: For the process steps job search and information we identified attitude and perceived enjoyment as the main acceptance criteria. Primarily, a negative attitude toward chatbots was observed among the applicants. They needed complementary features to use chatbots and the functions should be advanced. Benefits of the chatbots were not perceived by the participants.

However, using the support of digital assistants on job finding was approached more positively in the case that it is advanced and well presented. If the candidates notice that the answers are generic, they evaluate their experience as bad, leading to the decision of not using the application in the future. Two participants would not even use the chatbot in the first place because they would rather have questions or information about the company, or the application answered by a human than by a machine. An interviewee mentioned:
"I have not yet found the use case where I would say that this is a chatbot that I would use on a daily or weekly basis to chat with and that gives me an answer that I would not get anywhere else. (Account Manager)."

For the general questions about the company or application process, three participants would use the chatbot and found it useful. The quality and presentation of the chatbot is decisive whether they use the digital assistant or not, as one applicant states:

"The frustration can quickly become an issue, if the chatbot gives the same generic answers on differently formulated questions again and again. (Management Associate)."

The complementary functions of the chatbots, however, were positively assessed. All participants found chatbots very interesting to use for finding job opportunities. They were willing to try it. When asked whether users could rely on the job suggestions from the chatbots, the following requirements were made of the digital assistants: Several interesting posts should be proposed. If there was only one hit, the participants would search again themselves. The questions and answers must be very well maintained. Specific questions should be asked about the competences and skills. The results of this work also show that such digital assistants can support the candidates at numerous points, but the behavioral intent of the candidates depends on the perceived ease of use.

"Maybe there are people who use chatbots much more than I do, but for me personally the trust in them is condition on the fact that I would rather cross-check on my job opportunities. Of course, it could be that I have already interacted with a bot 10 times and then realized that everything really works, and nothing is left out. Then it becomes natural and at some point, it is adapted. (Account Manager)."

According to the participant, the adoption of the chatbots takes time, and one must be able to affirm the results brought by the bot to develop trust.

Application: For the process step application we identified anxiety and trialability as the main acceptance criteria. Conclusively, both recruiters and managers referred to their hesitance to use video applications to not scare important talents away and discourage candidates from applying. One manager emphasized if there is additional work for the applicants, they can easily allow themselves to cancel the application process in today's job market.

When it comes to the experience of the applicants, two of the interviewees had experience with video applications and they did not know if their videos were evaluated by an algorithm or a human. Both applicants reacted very positively to this new application form as they found it more personal than cover letters. 
Table 4. User acceptance variables mapped to the recruitment process

\begin{tabular}{|c|c|c|c|}
\hline $\begin{array}{l}\text { Phase: Example } \\
\text { of AI technology }\end{array}$ & Recruiter & Manager & Applicant \\
\hline $\begin{array}{l}\text { Job } \\
\text { advertisements: } \\
\text { Automated } \\
\text { analysis of job } \\
\text { advertisements }\end{array}$ & $\begin{array}{l}\text { Job relevance: AI can support the creation of job } \\
\text { descriptions as long as these requirements are } \\
\text { fulfilled: Solution must be timesaving, AI can analyze } \\
\text { multiple languages and must be familiar with general } \\
\text { regulations, Compatible with applicant tracking } \\
\text { system. }\end{array}$ & & \\
\hline $\begin{array}{l}\text { Job search: } \\
\text { Search query } \\
\text { personalization }\end{array}$ & & & \multirow{2}{*}{$\begin{array}{l}\text { Attitude and perceived enjoyment: } \\
\text { Experience and perceived benefits } \\
\text { play a role in whether the applicant } \\
\text { decides to use the AI application } \\
\text { and trust it or not. }\end{array}$} \\
\hline $\begin{array}{c}\text { Information: } \\
\text { Conversational } \\
\text { agents }\end{array}$ & & & \\
\hline $\begin{array}{l}\text { Application: AI } \\
\text { video analysis }\end{array}$ & \multicolumn{2}{|c|}{$\begin{array}{l}\text { Anxiety: Fear of deterring or losing talents through false selection criteria. AI } \\
\text { must recognize potentials for the company. }\end{array}$} & $\begin{array}{l}\text { Anxiety: AI-video analysis, } \\
\text { applicants choose the company that } \\
\text { does not use AI-video analysis in } \\
\text { recruitment, } \\
\text { Trialability: Applicants want to see } \\
\text { their own results. Some AI } \\
\text { recruiting tools already offer this } \\
\text { possibility to prepare for interviews. }\end{array}$ \\
\hline $\begin{array}{l}\text { Evaluation and } \\
\quad \text { selection: } \\
\text { Automated pre- } \\
\text { screening reports }\end{array}$ & $\begin{array}{l}\text { Job relevance: Time saving when there are many } \\
\text { applications. Candidates that definitely do not fit } \\
\text { based on the skillset can be sorted out directly and } \\
\text { faster. Support the management of applicant } \\
\text { documents. Coordination of appointments. } \\
\text { Complexity: Clear presentation of results and easy to } \\
\text { understand. } \\
\text { Anxiety: Fear of losing valuable talents that would be } \\
\text { suitable for other positions. } \\
\text { Trialability: To gain trust, the decision of the AI } \\
\text { should be compared with the own decision. It should } \\
\text { be checked whether they match or not. }\end{array}$ & $\begin{array}{l}\text { Job relevance: Pair } \\
\text { programming, active } \\
\text { souring, pre-selection; } \\
\text { Complexity: focus lies } \\
\text { on the main selection } \\
\text { criteria, results of AI } \\
\text { analyses are } \\
\text { understandable for } \\
\text { humans. }\end{array}$ & \\
\hline $\begin{array}{l}\text { Complementary } \\
\text { dimensions }\end{array}$ & \multicolumn{3}{|c|}{$\begin{array}{l}\text { Sense of Control: Detailed analysis and understanding the reasoning behind candidate rankings, ability to view the } \\
\text { candidates manually, and final decision lies in the human. } \\
\text { Trust: Understand how the algorithm works and learns, as this is the only way to gain confidence in the solution, build } \\
\text { trust and cross check the AI selection to build confidence. }\end{array}$} \\
\hline
\end{tabular}

Nevertheless, two interviewees pointed out that a video application is one-sided, and they would rather answer the questions of the recruiter on the phone or an interview than in an unfamiliar and time-consuming environment. Additionally, whenever participants knew that an AI was involved in the selection process, they stressed that this could lead them to think more about what words they used in their CV or video. It even happened that they tried to trick the machine.

The advanced features of an AI-based software that prepares the applicants for the interviews would be used by all candidates for training and met with great interest among the respondents. Furthermore, the applicants stated their indifference for the usage of AI-based technology in the recruitment process, however, they wanted to be informed about the AI at an early stage.

Evaluation and Selection: For the process step evaluation and selection we identified job relevance, complexity, anxiety and trialability as the main acceptance criteria. Evaluation and selection phase of the candidates with AI support was observed to be the most critical phase that raised concerns for all stakeholders. The most frequently mentioned criteria used to establish trust of recruiters and manager are the selection and weighting criteria, the clear presentation of the AI analysis, and understanding and testing how the algorithm works. Trialability and social influence were observed to be important for easy acceptance of the recruiters. The complementary features to funnel the candidates, in the case that an applicant is more suitable for another position, were a must for both recruiters and managers not to miss a valuable applicant in the process.

The evaluation process begins with the definition of the criteria, which the AI analyzes and evaluates the candidates. One challenge here is that every department and every team in a company has different requirements, otherwise the specifics of the company are lost. Additionally, it is difficult to define and weight the selection criteria for a specific position at the beginning. According to one recruiter:

"I often have the case that three candidates are invited for a personal interview, but they are actually all completely different and have a different focus and skill set. They all fit in their own way and then the team has 
to decide what they need most or what fits best. They often don't know this at the time of the vacancy. (Recruiter).",

One participant had the opinion that the algorithm should be based on empirical evaluation and scientific principles. For the recruiters to build trust in the AI, they would test the AI at the beginning by comparing the machine's decision with their own. A match would lead to more confidence in the artificial intelligent algorithms among the recruiters and they would choose to use the technology. With a large number of applicants, an AI can help the HR staff to manage the applicant funnel, and directly reject the unsuitable persons. This is affirmed by the following statement of a recruiter:

"Especially for software developers it is very difficult to find candidates. If five people apply for the job, they should not be directly rejected by an AI. On the other hand, I receive over 100 applications within half a week and I can't keep up with all the applications. Only every tenth candidate makes a step forward in the process. An AI could help to sort out the others directly. (Recruiter).",

All recruiters reported cases where an applicant is not suitable for the position for which he/she applied for but has the right qualifications for another position in the company. AI must be able to identify such a potentials talent, not only the right talent for a specific job.

Video analysis raised concerns. There are interpersonal aspects that an AI cannot perceive in a video. Another recruiter criticized the presented AI application for creating personality profiles and emphasized that the situation is unnatural for the some of the candidates are nervous. An AI must be able to take this into account. The presented software analyses the facial expressions, gestures, and the choice of words of the candidates with the help of AI. This led, again, to the question about the release of these analysis criteria. The applicants found the AI usage in video analysis scary and frightening. They stated that employers and AI must be aware that this is an unnatural situation and should be taken into account. The challenge of creating transparency was mentioned by managers, recruiters, and applicants.

When it comes to the interpersonal aspect, the partnership between manager and candidate, managers didn't see any advantage of the use of AI. The managers justified the low level of trust in the automated processes by citing their limited experience with AI. Managers need to build trust in the AI, just as they need to build trust in the recruiter who is recruiting the right candidates for their open positions. This trust is based on many years of cooperation between manager and recruiter. To build trust in the AI like in the recruiter, they would review the AI's analysis results with their own selection. To prevent prejudices, managers would also not make use of advance information from AI before actually meeting the candidate. Additionally, the managers were of the opinion that all existing applicant data should be included in the AI analysis. According to one manager:

"For me, the video is just a piece of the puzzle in a complete picture. This is not the puzzle piece where I say: seventy percent of my opinion is based on this automated video analysis. I would not trust the AI enough for that, for a start. (Fellow Software Engineer)."

One manager stated if he had a lot of time, he would deal more intensively with the application documents, and the AI analysis would only be a second opinion. However, if he was busy, the summary would help him to narrow down the group of applicants to a small number.

Funneling the candidates was another feature both managers and recruiters were willing to include. AI must not only filter out the skills set of candidates for a position but must also recognize potential talents that fit well into the company. Above all, a clear and understandable summary concentrating on the essentials of the AI analysis was considered important for all interviewed managers and recruiters. The most important prerequisite for the acceptance of this AI technology is for all interviewed recruiters to understand how the algorithm works and learns, as this is the only way to gain confidence in the solution, whereas the most important criteria for the managers was to build trust and cross check the AI selection to build confidence.

Complementary dimension: Covering all process steps, we identified sense of control and trust as complementary dimensions affecting acceptance. As long as final decision-making power in this field of application of AI is still with the human being, the recruiters saw no risks of AI replacing their jobs in using the AI-based software. Moreover, social influence was observed to be another factor for recruiters' motivations to adopt the technology. If the AI application is already being used by several companies in the marketplace, then a surveyed recruiter would trust the algorithm directly.

The perception of benefit of an AI also depended on the size of the company. Small and medium sized companies operating in a highly competitive market should not miss their chance to meet interesting candidates who have been rejected by an AI because they do not have the right keywords on their CV. Thus, a detailed analysis and understanding of the reasoning behind candidate rankings were considered to be important for all interviewed recruiters and managers.

When recruiters were asked at which further steps of the application process an AI can help them with their 
work by means of automated subprocesses, their response resulted to new areas of application: The HR staff wanted an AI that, for example, automatically searches its own applicant database for suitable candidates when a new job advertisement is created. Furthermore, they can imagine an AI for appointment coordination that recognizes free appointments in the interview participants' calendars and suggests them. Once the application process has been completed and the right candidate has been hired, an AI can provide support for operational tasks. For example, it can store the new employee in the company's internal personnel information system, including health insurance or assignment to the salary structure. A recruiter says that an AI would be useful to her if she would independently check that the applicant documents are up-to-date and, if necessary, request the new information from the candidate.

\section{Discussion}

All participants stated their understanding of the benefits of using AI recruitment process. Recruiters and managers were aware of the potentials and their job relevance. Yet, they emphasis some criteria to have a successful launch of the system: multilingualism, compatibility with other information systems to manage the existing database, and appointments were some of the complementary features stated to smooth the adoption process and reduce the workload. Transparency, trialability, and a sense of control are the key components to developing trust between $\mathrm{AI}$ and the relevant stakeholder to ease the acceptance and overcome the fear dimension of anxiety variable and complexity that unease the acceptance. Employees feared deterring the talent away, whereas applicants stated low willingness to use AI in video analysis in recruitment. The complexity variable was clearly tied to understanding how the algorithm works and trusting the decisions of the AI, such as the right criteria and right weighting of the criteria.

The findings from the previous studies suggest that recruiters and managers need to be able to match the decisions of the AI with their hypothetical decisions. Participants emphasized that it is easier to trust the AI if the decision is based on triable and evaluated based on empirical principles. Therefore, we suggest the use of approval nodes/ checkpoints where the respective person chooses from the AI presented alternatives (different weighting of the criteria and different wording of the job posting) can ease the adoption of the technology by recruiters and managers by enhancing trust. Moreover, understanding the reasoning behind decisions taken by the AI through clear summaries (why an applicant was rejected or selected, positives and negatives) provides more insight and flexibility, thus results in higher chances of a successful adoption. If we generalize our findings, a ranked list of candidates rather than a final decision gives the respective person the feeling of more control and flexibility over the process, which eases adoption. It also builds on the correctability rule offered by Zhang and his colleagues [31] to prevent unfair decisions by providing several options to review and modify the AI's decision. In contrast to Lee and Choi's findings [32], applicants did not state pleasure in interacting with technology based agents to gather information about the respective companies and showed clear aversion to the usage of chatbots. It is thus important for the applicants to understand the benefits of AI and complement the chatbot information function with digital assistants. This assistance helps the applicants find the right jobs since applicants are inclined to associate positive experiences with it. They need to make sure the system is fair, and it eases their application process. When the applicants receive intrinsic benefits from using $\mathrm{AI}$ in the recruitment process, they are more likely to apply for the job that they know uses AI in the recruitment process [33]. Supporting what Sylva and Mol suggest, when the features and procedures of e-recruitment are more advanced, candidates appear more satisfied [34]. Thus, building on complementary features, communicating benefits, and transparency on how the system works will be a key factor for successful adoption of the AI in the recruitment, including video analysis, positively changing the participants' attitude.

Our study supports the optimism, discomfort, and insecurity dimensions suggested by Parasuraman \& Colby [26], but did not reveal any effect of innovativeness on the tendency to adopt AI in recruiting. The study improves the literature by suggesting guidelines and process modeling standards following Sidorava and Rafiee [35] to support AI governance. Challenges arise in connection with the machine learning of the AI that makes decisions. The system must only learn what it is supposed to learn, otherwise, an AI can be fed with prejudices. For example, Amazon 2014 developed an algorithm that filtered out the most promising candidates from several application texts. Amazon's AI was trained to vet applicants by observing patterns in resumes submitted to the company over a 10year period. The system taught itself that male candidates were preferable; a reflection of male dominance across tech industry. Basic problems of machine learning of the AI were clarified [36]. We identified the impact of trust and communication of AI's use as the key areas to increase the perceived control feeling. We also identified the effect of AI in the recruitment process, thus suggest mechanisms to 
increase the control and flexibility over the processes. To avoid being biased in our decision making, we present the following suggestions: (1) ranked array of options with its reasoning rather than a final decision should be provided to avoid biased decision-making system; (2) checkpoints/approval nodes should be introduced via a partial automation of subprocesses; (3) fixed enterprise-wide set rules should be introduced to avoid distortion. Checkpoints and approval nodes provide inference between the steps of triple-loop human machine learning model [37] previously used in generating design outcomes: Framing, evaluation, and adjustment; (4) transparent goal setting process should be ensured, before introducing an AI solution. The objectives of its use must be defined and all relevant stakeholders should be informed; (5) whoever uses AI solution must ensure that a human has the final authority to make important decisions; (6) solutions should be empirically evaluated before its launch by trying out it on the past data; (7) there should be an obligation to inform applicants on which data have been collected, used, and analyzed for which purpose; and (8) continuous monitoring and retraining should be ensured via a blended decision-making process. Periodical retraining the machine learning by a blended decisionmaking process, improves the performance of the system [38], resulting in more accurate results.

Prior studies have generated insights by outlining the impact of fairness in the adoption of AI recruiting system [14, 39], impacts of machine learning [38], the mechanisms and standards to prevent bias, and increase the control. Besides the aforementioned contributions, our study also contributes to the literature by bringing suggestions on the mechanisms to ease the adoption of AI recruiting using the TAM.

\section{Limitations and Future Research}

Whereas the results of our study provide essential contributions to both research and practice, we acknowledge certain limitations that should be kept in mind while interpreting results and implications of our research. The country where the study was conducted has some regulations in the field of AI with regard to the General Data Protection Regulation. According to Article 22, the final selection of candidates must still be made by a human being. Anything else is a violation. This study should be further extended in different countries where regulations differ. The quantitative study should optimally supplement qualitative research results. Building upon 15 interviews gives latitude for misinterpretations, although the cases and interviews were carefully chosen. Extending this research to different companies and increasing the number of interviewees would complement this research. Additionally, the acceptance research of this paper should be complemented by related theories, e.g., the diffusion research in the future, to investigate company/ group level acceptance criteria describing the adaption behavior. Our study needs to be further extended to draw the processes, determine where the checkpoints are, and set out rigid rules and guidelines to educate the companies and employees. Furthermore, research should be performed to compare the employees' attitude and applicant from different sectors.

\section{Conclusion}

This paper reports a study conducted to offer mechanisms and guidelines for adopting the use of AI in recruitment. The acceptance theories we considered explain the acceptance criteria and barriers that were slowing the adoption process. Our interviews with the participants suggest that transparency, complementary features like sense of control play key roles. This paper contributes to the literature by offering ways to positively influence users' attitudes and perceptions with an increased control and knowledge. This research also contributes on the acceptance criteria for AI and the mediums to overcome the problems that rise with machine learning. The recruitment is currently undergoing a transformation due to new technologies, which employees and applicants intensively have to deal with. However, the stakeholders in the recruitment process will always be the key indicator of a successful acceptance of AI-based recruitment technologies.

\section{References}

[1] Powell, W.W. and K. Snellman, The knowledge economy. Annu. Rev. Sociol., 2004. 30: p. 199-220.

[2] Whysall, Z., M. Owtram, and S. Brittain, The new talent management challenges of Industry 4.0. Journal of Management Development, 2019.

[3] The changes covid-19 is forcing on to business. The Economist 2020 [cited 2020 June, 26]; Available from: https://www.economist.com/briefing/2020/04/11/thechanges-covid-19-is-forcing-on-to-business.

[4] Fankiewicz, B.C.-P.T., Digital Transformation Is About Talent, Not Technology. Havard Business Review, 2020.

[5] van Esch, P. and M. Mente, Marketing video-enabled social media as part of your e-recruitment strategy: Stop trying to be trendy. Journal of Retailing and Consumer Services, 2018. 44: p. 266-273.

[6] Lee, I., An architecture for a next-generation holistic erecruiting system. Communications of the ACM, 2007. 50(7): p. 81-85.

[7] Verhoeven, T., Künstliche Intelligenz im Recruiting, in Digitalisierung im Recruiting. 2020, Springer. p. 113128. 
[8] Russell, S. and P. Norvig, Artificial intelligence: a modern approach. 2002.

[9] Jäger, W., Digitalisierung im Recruiting (Recruiting 4.0). Digital HR: Smarte und agile Systeme, Prozesse und Strukturen im Personalmanagement, 2018. 14054: p. 213-223.

[10] van Esch, P. and J.S. Black, Factors that influence new generation candidates to engage with and complete digital, AI-enabled recruiting. Business Horizons, 2019. 62(6): p. 729-739.

[11] Ochmann, J. and S. Laumer, AI Recruitment: Explaining job seekers' acceptance of automation in human resource management.

[12] Yu, H., C. Liu, and F. Zhang, Reciprocal recommendation algorithm for the field of recruitment. Journal of Information \& Computational Science, 2011. 8(16): p. 4061-4068.

[13] Strohmeier, S. and F. Piazza, Artificial intelligence techniques in human resource management-a conceptual exploration, in Intelligent techniques in engineering management. 2015, Springer. p. 149-172.

[14] Ochmann, J. and S. Laumer, Fairness as a Determinant of AI Adoptionin Recruiting: An Interview-based Study. Technology. 12: p. 15-2019.

[15] Davenport, T.H. and J.E. Short, The new industrial engineering: information technology and business process redesign. 1990.

[16] Collier, D. and C. Zhang, Can We Reduce Bias in the Recruiting Process and Diversify Pools of Candidates by Using Different Types of Words in Job Descriptions? 2016.

[17] Miller, C.C., Can an algorithm hire better than a human. The New York Times, 2015. 25.

[18] Janssen, A., et al., Virtual assistance in any context: a taxonomy of design elements for domain-specific chatbots. Bus Inf Syst Eng. 2020.

[19] Petry, T., Digital HR: Veränderung des Personalmanagements durch digitale Medien und Technologien, in Media Management. 2018, Springer. p. 43-56.

[20] Teetz, I., 9 Künstliche Intelligenz im Recruiting. Digital HR: Smarte und agile Systeme, Prozesse und Strukturen im Personalmanagement, 2018. 14054: p. 225.

[21] Escalante, H.J., et al. Design of an explainable machine learning challenge for video interviews. in 2017 International Joint Conference on Neural Networks (IJCNN). 2017. IEEE.

[22] Libert, K., E. Mosconi, and N. Cadieux. Human-Machine Interaction and Human Resource Management Perspective for Collaborative Robotics Implementation and Adoption. in Proceedings of the 53rd Hawaii International Conference on System Sciences. 2020.

[23] Sohn, K. and O. Kwon, Technology acceptance theories and factors influencing artificial Intelligence-based intelligent products. Telematics and Informatics, 2020. 47: p. 101324.

[24] Davis, F.D., Perceived usefulness, perceived ease of use, and user acceptance of information technology. MIS quarterly, 1989: p. 319-340.
[25] Davis, F.D., R.P. Bagozzi, and P.R. Warshaw, User acceptance of computer technology: a comparison of two theoretical models. Management science, 1989. 35(8): p. 982-1003.

[26] Colby, C.L. and A. Parasuraman, Techno-Ready Marketing: How and Why Customers Adopt Technology. 2001: Simon and Schuster.

[27] Succi, M.J. and Z.D. Walter. Theory of user acceptance of information technologies: an examination of health care professionals. in Proceedings of the 32nd Annual Hawaii International Conference on Systems Sciences. 1999. HICSS-32. Abstracts and CD-ROM of Full Papers. 1999. IEEE.

[28] Lee, Y., K.A. Kozar, and K.R. Larsen, The technology acceptance model: Past, present, and future. Communications of the Association for information systems, 2003. 12(1): p. 50.

[29] Parasuraman, A., Technology Readiness Index (TRI) a multiple-item scale to measure readiness to embrace new technologies. Journal of service research, 2000. 2(4): p. 307-320.

[30] Mayring, P., Qualitative inhaltsanalyse, in Handbuch qualitative Forschung in der Psychologie. 2010, Springer. p. 601-613.

[31] Zhang, X., et al. Developing Fairness Rules for Talent Intelligence Management System. in Proceedings of the 53rd Hawaii International Conference on System Sciences. 2020.

[32] Lee, S. and J. Choi, Enhancing user experience with conversational agent for movie recommendation: Effects of self-disclosure and reciprocity. International Journal of Human-Computer Studies, 2017. 103: p. 95-105.

[33] Van Esch, P., J.S. Black, and J. Ferolie, Marketing AI recruitment: The next phase in job application and selection. Computers in Human Behavior, 2019. 90: p. 215-222.

[34] Sylva, H. and S.T. Mol, E-Recruitment: A study into applicant perceptions of an online application system. International Journal of Selection and Assessment, 2009. 17(3): p. 311-323.

[35] Sidorova, A. and D. Rafiee. AI Agency Risks and their Mitigation through Business Process Management: a Conceptual Framework. in Proceedings of the 52nd Hawaii International Conference on System Sciences. 2019.

[36] Dastin, J., Amazon scraps secret AI recruiting tool that showed bias against women. San Fransico, CA: Reuters. Retrieved on October, 2018. 9: p. 2018.

[37] Seidel, S., et al., Autonomous tools and design: a tripleloop approach to human-machine learning. Communications of the ACM, 2018. 62(1): p. 50-57.

[38] Crowston, K. and F. Bolici. Impacts of machine learning on work. in Proceedings of the 52nd Hawaii International Conference on System Sciences. 2019.

[39] Ebrahimi, S. and K. Hassanein, Can the Use of Data Analytics Tools Lead to Discriminatory Decisions? 2019. 